\title{
CURRENT STATE OF ART ON DEVELOPMENT OF FILM-FORMING DECONTAMINATION MATERIALS
}

\author{
Daniela PULPEA \\ Military Technical Academy, Bucharest, Romania \\ trincu.daniela@yahoo.com
}

\begin{abstract}
Chemical and radioactive contamination of surfaces can occur in a wide variety of industrial and military applications, but they can also be the consequences of an industrial accident or terrorist attack. This paper makes a comparative study of the strippable or temporary coatings developed and used in the field of chemical and radioactive decontamination. The purpose is to classify existing decontaminant film-forming substances and to determine the optimum properties for such materials.
\end{abstract}

\section{Keywords: strippable coating, decontamination, polymer, plasticizer, additive}

\section{Introduction}

In the field of CBRN defence, it is essential to take into account the performance and the ease of use of the decontamination materials.

This paper deals with the study of different properties of strippable coatings that are used in the field of decontamination of chemical warfare agents, radioactive substances and heavy metals.

\section{Appling the strippable coating}

A strippable coating is applied to a contaminated surface as a liquid by roller, brush or spray. After the mixture dries out it forms a polymeric film which can simply be peeled away, without deteriorating the substrate surface. A simplified representation of the process can be notice in Figure 1.

The coating can be used on different contaminated surfaces, that can be porous or smooth, but usually it is desirable to be used on common surfaces like:

- stainless steel, carbon steel,
- aluminium, copper, brass,

- plexi-glass, polyvinylchlorine, epoxicoated surfaces, painted surfaces,

- concrete, glass and wood. [4]

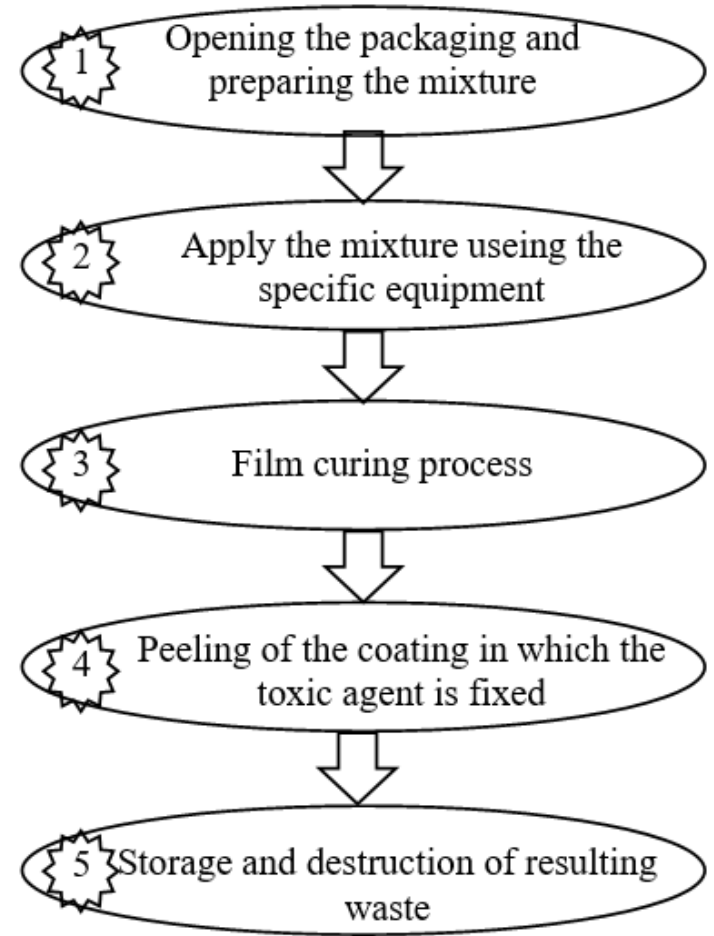

Figure 1: Simplified application process 
Because most of the strippable coatings are soluble in water, the equipment used in the application process can easily be cleaned by washing with water. [3]

Viscosity is an important property of the material and is generally very low so the coating can be spread evenly and it can penetrated the pores of the contaminated surface. A strippable coating container can stay opened only a short period of time, because the viscosity can increase rapidly due to evaporation of small quantities of water. So, the applying method must be perfected to last only a small amount of time. Besides the viscosity problem this is also beneficial to the health of the personnel responsible for applying the coating over contaminated surfaces, considering that they are not supposed to spend a long in a toxic environment.

\subsection{How it works}

The decontamination mixture needs to have a good contact in order to stick to the surface, but in the same time the adhesion after curing must be low, to allow the peeling of the coating.

It is necessary to maintain an optimal balance between allowing ease of removal and maintaining a proper adhesion of the coating.

In order to stick to a surface the strippable coating needs to have a particular value of adhesion (binding force between two different materials) and cohesion (binding force between two similar materials). The adherence to a surface is determined by a combination of the molecular forces of the coating sticking to itself as well as holding onto the contaminated surface.

The contaminant can be fixed in the polymeric film in two ways: by a complexation mechanism (in which a chelating agent forms a bonding with the toxic agent) or an adsorption mechanism (in which the toxic agent is linked to an adsorbent agent through van der Waals forces or covalent bonding). [6]

\subsection{Composition characteristics}

The coating composition is an important factor that can vary at the same time with other properties like viscosity, wetting of the surface, thickness of thin layer, drying time etc. The percentage of main materials used to manufacture a strippable coating is represented in Figure 2. All the substances that are added to the polymeric composition are influencing the properties required to achieve effective decontamination of surfaces. Several materials used to make strippable coatings for decontamination purposes are listed in Table 1.

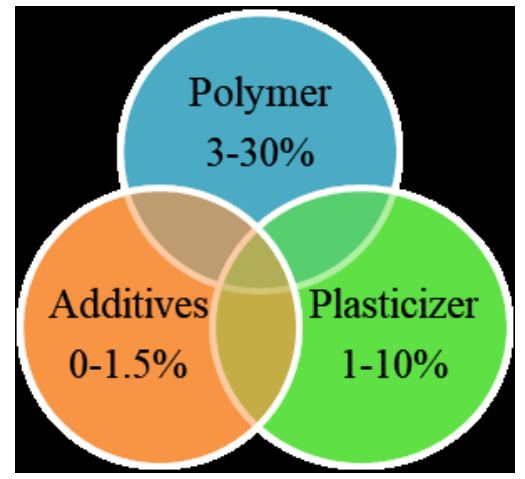

Figure 2: Strippable coating aqueous solution in its simplest form.

Most often, PVA is used as the basis of the strippable coatings because it is soluble in water and biodegradable [12]. It has good strength and is used as a binder in most common plastic paints. It is available in very large amounts. However, PVA is not the ideal material due to the fact that under wet conditions it may not be possible for the water-based film to dry sufficiently in order the stripping of a continuous intact layer [7].

Also, PVA has excellent film forming, water-solubility, adhesion, emulsification and barrier properties, and it has been used in fibres, films and adhesive agents widely [8].

Among other properties PVA is safe in use since it is a non-toxic water-soluble polymer, and also, is a non-carcinogenic material [10] [11].

Water is chosen based on the fact that PVA is soluble in this solvent and, being used in large quantities, it has a low-cost. 
The plasticizer plays the role of reducing the viscosity of the aqueous solution and increase the flexibility of the dried membrane. As a result, it can improve the efficiency of operations like spreading, applying, peeling, and recovering of the strippable coating. In most cases glycerol is used as an additive, that makes the molecules more flexible and decrease the attraction between polymer chains, and it is safe for human and environment [3].

In strippable coatings, additives are included to modify different properties for obtaining the optimal material in terms of viscosity, drying time of the foil, decontamination factor, colorimetric indication, shear resistance, tensile strength and elasticity.

Table 1 Materials used in the fabrication of strippable decontamination coatings

\begin{tabular}{|c|c|}
\hline Solvent & $\begin{array}{l}\text { Water }[3][4][6][7] \\
\text { Ammonium hydroxide (ammonia water) [1] } \\
\text { Ethanol[4] } \\
\text { Sodium hydroxide (caustic soda) [1] }\end{array}$ \\
\hline Solute (polymers) & $\begin{array}{l}\text { Polyvinyl alcohol }[3][4][6][7] \\
\text { Polyvinyl acetate[4] } \\
\text { Low density polyethylene[2] } \\
\text { Polymeric resins[1] } \\
\text { - acrylic polymer (Carboset } 514 \mathrm{H}) \\
\text { - copolymer styrene and maleic anhydride (SCRIPSET) } \\
\text { - sulfonated polystyrene polymers (Versa TL) }\end{array}$ \\
\hline Plasticizer & $\begin{array}{l}\text { Glycerol, Ethylene glycol, Diethylene glycol, Triethylene glycol, } \\
\text { Propylene glycol, Trimethylene glycol, Tetramethylene glycol, } \\
\text { Pentamethylene glycol, Hexamethylene glycol; [3] }\end{array}$ \\
\hline Additives & $\begin{array}{l}\text { Lactic acid, Alcohols, Acetone, Citric acid, Acetic acid, } \\
\text { Polyethylene glycol, Phosphorous acid[4] } \\
\text { Tensides: lauryl sulphonate [4] } \\
\text { Chelating agents (masking agents)[5] [6] [7] } \\
\text { - EDTA, DTPA, EGTA, TTHA } \\
\text { Curing resins[4] } \\
\text { - formaldehyd and melamine resins } \\
\text { Colorimetric indicators[5] [8] }\end{array}$ \\
\hline
\end{tabular}

The additives are added to the mixture because they are required to achive essential properties (dispersant, catalyst, drier or curing agent), they are conferring an additional desirable property (adhesion promoter, freeze/thaw stabilizer) and they can overcome an undesirable side effect (anti-foam, anti-flooding, anti-skin). [13] In particular, different additives are used to enhance the decontamination factor, to change colour when a toxic agent is present or to act like a masking agent.

It is possible to add a filler in the aqueous solution that can be one or more materials such as: silica sand, calcium carbonate, clay, fly ash, blast furnace slag and sand.
Since the filler has the effect of reducing the adhesion of the membrane to the structural surface, is important to take into account the quantity of filler that is needed to be added in the mixture, in order to facilitate an easy peeling of the coating. Therefore, the cleaning operation of the strippable coating from the surfaces can be improved by adding an appropriate filler [3].

\section{Advantages of using strippable coatings}

Given the human nature, when working in laboratories or factories, with toxic or radioactive substances, there is always the risk of accidental contamination of the 
objects and surfaces, despite the fact that the procedure is followed step by step.

Even if a contamination is not present the equipment used in such a facility must be decontaminated periodically.

Conventional methods used in decontamination have drawbacks, most of which destroy surfaces by the use of: caustic substances such as sodium or calcium hypochlorite, pressurized water jets, hot gas jets, or a mechanical operations. These can cause corrosion, paint degradation or abrasion of surfaces, which is not desirable if the equipment is sensitive or if it is intended to be put into operation as soon as possible. Another important aspect is that the decontamination should take place as soon as possible and is desirable to diminish the time a person stays in contact with a contaminant substance.

In these situations the strippable coatings can bring the following advantages to the decontamination process:

- Decontamination of chemical warfare agents, radioactive agents of heavy metals.

- Reduced time for decontamination.

- The contaminant can be contained an isolated inside the polymer matrix, avoiding toxic material from spreading.

- Reduced exposure of staff (the presence of personnel is required only when applying and exfoliating the film, not during the curing process).

- Does not interact with the surfaces

- They can be eco-friendly and biodegradable.

- They have a simple and fast application procedure.

- Subsequent contamination of water is eliminated.

- The coating has the possibility of being destroyed by incineration after use, which does not result in toxic products.

- The toxic agent is fixated in the polymer matrix, so it can be easily manipulated and transported without the risk of secondary contamination.
- Reduced waste volume after decontamination, compared to other methods.

- Some of them can change colour when they are exposed to a toxic material.

- It can also be used as a protective coating, applied prior to contamination, which can retain the toxic material on its surface.

\section{Strippable coatings features}

While the coatings are drying they lose an important amount of water by evaporation, and they tend to be weakened and lose flexibility. When a peeling force is applied to the weakened membranes they are easily torn and this process becomes difficult and time-consuming. The relative values of coatings characteristics of suitable membranes for decontamination are listed in Table 2.

In order for the dried membrane to be peeled off from a surface without tearing it is necessary to take into account the thickness of the coating.

Table 2 Relative values of coatings characteristics

\begin{tabular}{ll}
$\begin{array}{l}\text { Thickness of dry } \\
\text { membrane }(\mathbf{m m})\end{array}$ & $0.2-0.5$ \\
\hline $\begin{array}{l}\text { Degree of } \\
\text { polymerization }\end{array}$ & $1000-3000$ \\
\hline Viscosity $(\mathbf{P a *} \mathbf{s})$ & $0.04-0.10$ \\
\hline $\begin{array}{l}\text { Decontamination } \\
\text { factor }(\%)\end{array}$ & $10-95$ \\
\hline
\end{tabular}

Also, it is desirable to have membranes with a degree of polymerization between 1000 and 3000 considering that only this type of aqueous solutions can form peelable tough coatings. If the degree of polymerization is not between these values the desired toughness of the membrane cannot be achieved $(\mathrm{Dp}<1000)$ or the viscosity of the aqueous solution becomes too high for uniform spreading ( $\mathrm{Dp}>3000)$. The thickness of the membrane should be taken into account when is needed to 
estimate if the coating is peelable or not. If the dry membrane is too thick then it is hard to be exfoliated, and if it is too thin exfoliation may be impossible. Also, the thickness of the membrane depends on the viscosity of the aqueous solution. If the viscosity is small, then the membrane becomes thin, if the viscosity becomes low, the membrane gets relatively thick.

The decontamination factor has a wide range of values considering that it depends on:

- The type of surfaces that are needed to be decontaminated.

- The type and the state of aggregation of the contaminants.

- The viscosity of the aqueous solution.

- The additives that are introduced into the solution and which can improve this factor.

Viscosity is the most discussed feature of the aqueous solution through it may vary with the smallest changes that take place in solution. The addition of plasticizer can reduce the viscosity of the aqueous solution and in the same time increase the flexibility of the dried membrane and this improves the applying process. Depending on viscosity of the solution, the material can be applied either by brushing (onto horizontal or vertical surfaces) pouring onto surfaces or spraying by compressed air. [3] [4] [6] All the components of an aqueous polymeric solution can influence the viscosity of the final product. Therefore, an increase in viscosity can lead to changes in molecules mobility and solution ability to enter into the pores and cracks of the surface and that in the end can affect the decontamination capability.

\section{Conclusion}

Compared to the usual decontaminated methods, strippable coatings are convenient due to their capability to isolate the toxic substances, their ability to be relative easy to apply, and some of them have the capacity to spot the toxic material by changing colour.

In these circumstances it is preferable that in the future, several conventional decontamination methods to be replaced by strippable coatings.

\section{References}

[1] Lyle O. Malotky, Hazardous material removal using strippable coatings, Unite States Patent, 1992.

[2] Giambattista Guidi, Fabrizio Cumo, Livio de Santoli, LCA of strippable coatings and of steam vacuum technology used for nuclear plants decontamination, Clean Techn Environ Policy 12:283-289, 2010.

[3] Sakurai, Minato-ku, Lim, Kobayashi, Method for cleaning structural surface, European patent application, 1998.

[4] H. Weichselgartner, Decontamination with pasty pickling agents forming a strippable foil, Nuclear science and technology, 1991.

[5] H. Neil Gray, Betty Jorgensen, Donald L. McClaugherty, Andrew Kippenberger, Smart Polymeric Coatings for Surface Decontamination, Ind. Eng. Chem. Res. 2001, 40, 3540-3546.

[6] G. Toader, P.-O. Stănescu, T. Zecheru, T. Rotariu, A. El-Ghayoury and M. Teodorescu., Water-based strippable coatings containing bentonite clay for heavy metal surface decontamination, Arabian Journal of Chemistry, 2016.

[7] Kasper G. Andersson \& Jorn Roed, Removal of Radioactive Fallout from Surface of Soil and Grassed Surfaces Using Peelable Coatings, J. Environ. Radioactivity 22 (1994) 197-203.

[8] Jonathan G. Weis and Timothy M. Swager, Thiophene-Fused tropones as chemical warfare agent-responsive building blocks, ACS Macro Lett. 2015, 4, 138-142. 
[9] Jia, P.Y., Bo, C.Y., Hu, L.H., Zhou, Y.H., 2014. Properties of poly (vinyl alcohol) plasticized by glycerin. J. For. Prod. Ind. 3, 151-153

[10] DeMerlis, C., Schoneker, D., 2003. Review of the oral toxicity of polyvinyl alcohol (PVA). Food Chem. Toxicol. 41, 319-326.

[11] US Department of Health and Human Services, NTP Technical Report on the Toxicology and Carcinogenesis Studies of Polyvinyl alcohol in female B6C3F1 mice, 1998.

[12] Chiellini, E., Corti, A., D’Antone, S., Solaro, R., 2003. Biodegradation of poly (vinyl alcohol) based materials. Prog. Polym. Sci. 28, 963- 1014.

[13] Gerry Davison and Bruce Lane, Additives in Water-Borne Coatings. Royal Society of Chemistry: Cambridge. 2003. 